\title{
High Cardiovascular Fitness Is Associated with Low Metabolic Risk Score in Children: The European Youth Heart Study
}

\author{
JONATAN R. RUIZ, FRANCISCO B. ORTEGA, NICO S. RIZZO, INGA VILLA, ANITA HURTIG-WENNLÖF, \\ LEILA OJA, AND MICHAEL SJÖSTRÖM
}

\begin{abstract}
Department of Biosciences and Nutrition [J.R.R., F.B.O., N.S.R., M.S.], Unit for Preventive Nutrition, NOVUM, Karolinska Institutet, Huddinge, 14157, Sweden; Department of Physiology [J.R.R., F.B.O.], School of Medicine, University of Granada, Granada, 18012, Spain; Department of Public Health [I.V.], Estonian Centre of Behavioural and Health Sciences, University of Tartu, 50090, Estonia; Department of Clinical Medicine [A.H.-W.], Örebro University, Örebro, 70182, Sweden; National Institute for Health Development [L.O.], Estonian Centre of Behavioural and Health Sciences, Tallinn, 11619, Estonia
\end{abstract}

\begin{abstract}
The aim of the present study was to examine the associations of cardiovascular fitness (CVF) with a clustering of metabolic risk factors in children, and to examine whether there is a CVF level associated with a low metabolic risk. CVF was estimated by a maximal ergometer bike test on 873 randomly selected children from Sweden and Estonia. Additional measured outcomes included fasting insulin, glucose, triglycerides, HDLC, blood pressure, and the sum of five skinfolds. A metabolic risk score was computed as the mean of the standardized outcomes scores. A risk score $<75$ th percentile was considered to indicate a low metabolic risk. CVF was negatively associated with clustering of metabolic risk factors in children. Receiver operating characteristic curve analysis showed a significant discriminatory accuracy of CVF in identifying the low/ high metabolic risk in girls and boys $(p<0.001)$. The CVF level for a low metabolic risk was 37.0 and $42.1 \mathrm{~mL} / \mathrm{kg} / \mathrm{min}$ in girls and boys, respectively. These levels are similar to the health-related threshold values of CVF suggested by worldwide recognized organizations. In conclusion, the results suggest a hypothetical CVF level for having a low metabolic risk, which should be further tested in longitudinal and/or intervention studies. (Pediatr Res 61: 350-355, 2007)
\end{abstract}

$\mathrm{C}$ VF is as a direct marker of physiologic status and reflects the overall capacity of the cardiovascular and respiratory systems, and the ability to carry out prolonged physical exercise (1). High CVF during childhood and adolescence has been associated with a healthier cardiovascular profile during these years (2-5) and also later in life (6). Associations between high CVF and a favorable plasma lipid profile in both overweight and nonoverweight Spanish adolescents have been reported (3). Moreover, CVF has been associated with body fat (4), with features of the metabolic syndrome (2), and with arterial compliance (5) in young population, which supports the concept that CVF may exert a protective effect on the cardiovascular system from an early age. Recently, low CVF

Received August 18, 2006; accepted October 18, 2006.

Correspondence: Jonatan R. Ruiz, Ph.D., Karolinska Institutet, Department of Biosciences and Nutrition, Unit for Preventive Nutrition, NOVUM, 14157 Huddinge, Sweden; e-mail: ruizj@ugr.es

The Swedish part of the study was supported by grants from the Stockholm County Council (MS), and the Estonian part was supported by a grant from the Estonian Science Foundation No. 3277 and 5209, and by Estonian Centre of Behavioural and Health Sciences. JRR and FBO were supported by a grant from Ministerio de Educación y Ciencia de España (AP2003-2128, AP2004-2745).

DOI: 10.1203/pdr.0b013e318030d1bd has been considered as a risk factor in children and adolescents to the same extent as low HDL cholesterol (HDLC) or insulin resistance (7).

It is biologically plausible that high CVF provides more health protection than low CVF even in healthy children and adolescents, as has been found in adults $(8-10)$. Low CVF seems to be an independent predictor of metabolic syndrome in men and women (9), and low CVF could be another mechanism of overall cardiovascular disease. Moreover, CVF seems to prevent premature mortality regardless of body weight status or the presence of metabolic syndrome in adult men (10). Collectively, cross-sectional, longitudinal, and interventional studies support the notion that CVF is a key correlate of the metabolic syndrome phenotype in the young and adult population.

Despite evidence of the association between CVF and single cardiovascular disease risk factors in young and adult populations, whether health criteria values for CVF can be identified and the implications of these from the public health perspective are still uncertain. In this respect, several healthrelated threshold values of CVF have been suggested by worldwide recognized organizations $(11,12)$. However, no consensus exists regarding the minimum CVF level associated with a clustering of cardiovascular disease risk factors in children. It has been suggested that clustering of cardiovascular disease risk factors is a better measure of cardiovascular health in young people than single risk factors, and that composite risk score could, to some extent, compensate for day-to-day fluctuations in the single risk factors (7).

For public health strategies and preventive purposes, it is of interest to have evidence-based health criteria values for CVF from an early age. The aim of the present study was to examine the associations of CVF with a clustering of metabolic risk factors in children, and to examine whether there is a CVF level associated with a low metabolic risk.

\section{METHODS}

The study involved 1140 children aged 9-10 y, of which 873 (444 girls, 429 boys) from the Estonian and Swedish (539 and 334, respectively) part of

Abbreviations: AUC, area under the curve; CVF, cardiovascular fitness; ROC, receiver operating characteristic 
the European Youth Heart Study (EYHS) provided a complete data set. The EYHS is a school-based, cross-sectional study designed to examine the interactions between personal, environmental, and lifestyle influences on the risk factor for future cardiovascular diseases. Study design, selection criteria, and sample calculations have been reported elsewhere $(13,14)$. The local ethical committees approved the study (Örebro City Council no. 690/98, Huddinge University Hospital no. 474/98, and University of Tartu no. 49/30-1997). One parent or legal guardian provided written informed consent, and all children gave verbal consent.

Physical examination. Height, weight, and skinfold thickness (biceps, triceps, subscapular, suprailiac, and triceps surae) were measured by standardized procedures. A description of the measurements has been published elsewhere (4). Body mass index (BMI) was calculated as weight divided by height squared $\left(\mathrm{kg} / \mathrm{m}^{2}\right)$. The sum of five skinfold thicknesses was used as an indicator of body fat rather than BMI, because it has been suggested that BMI is not a good measurement of body fat in children (15), and because fatness rather than weight has been shown to be associated with poor health (16). Skinfold thickness has been shown to highly correlate with dual-energy x-ray absorptiometry-measured body fat percentage in children of similar ages (17). Identification of pubertal development was assessed according to Tanner (18). Pubertal stage was assessed by a researcher of the same gender as the child by brief observation. Breast development in girls and genital development in boys were used for pubertal classification.

Blood pressure. The systolic and diastolic blood pressures were measured with an automatic oscillometric method (Dinamap model XL, Critikon, Inc., Tampa, FL). The equipment has been validated in children (19). The subject was in a seated and relaxed position, and recordings were made every second minute for 10 min with the aim of obtaining a set of systolic recordings not varying by more than $5 \mathrm{~mm} \mathrm{Hg}$. The mean value of the last three recordings was used as the resting systolic and diastolic blood pressure, in $\mathrm{mm} \mathrm{Hg}$.

Blood samples. Serum concentrations of triglycerides, HDLC, glucose, and insulin were measured after an overnight fast. A detailed description of the blood analysis has been reported by Wennlöf et al. (20).

Clustering of metabolic risk factors. The clustering of metabolic risk factors was computed from the following variables: insulin, glucose, HDLC, triglycerides, skinfold thickness, and blood pressure (systolic and diastolic). Each of these variables was standardized as follows: standardized value $=$ (value - mean)/SD. The HDLC standardized value was multiplied by -1 to confer higher risk with increasing value for the purpose of calculating the metabolic risk. The standardized values of systolic and diastolic blood pressure were averaged. The metabolic risk score was calculated as the mean of the six standardized scores separately for boys and girls. Children being below the 75th percentile of the score were defined as having low metabolic risk, and children being at or above the 75th percentile of the score were defined as having high risk. Moreover, low (high) metabolic risk was considered when the individual had $<1 \mathrm{SD}(\geq 1 \mathrm{SD})$ of this score.

$\boldsymbol{C V F}$. CVF was determined by a maximum cycle-ergometer test as described elsewhere (21). Briefly, the workload was preprogrammed on a computerized cycle-ergometer (Monark 829E, Ergomedic, Vansbro, Sweden) to increase every third minute until exhaustion. Criteria for exhaustion were a heart rate $\geq 185$ beats per minute, failure to maintain a pedaling frequency of at least 30 revolutions per minute, and a subjective judgment by the observer that the child could no longer keep up, even after vocal encouragement. The power output was calculated as being equal to $W_{1}+\left(W_{2} \cdot t / 180\right)$, where $\mathrm{W}_{1}$ is a work rate at fully completed stage, $\mathrm{W}_{2}$ is the work rate increment at final incomplete stage, and $\mathrm{t}$ is time in seconds at final incomplete stage. The "Hansen formula" for calculated $\mathrm{VO}_{2 \max }$ in $\mathrm{mL} / \mathrm{min}$ was is equal to $12 \times$ calculated power output $+5 \times$ body weight in kilograms (21).

Statistical analysis. The data are presented as mean (SD) unless otherwise stated. All variables were checked for normality of distribution before the analysis, and transformations were applied when necessary. Skinfold thickness and triglycerides were logarithmically transformed, and the square root of insulin values was calculated. Untransformed data are presented for ease of interpretation. Gender differences were assessed by ANOVA, inasmuch as there was a significant interaction between gender and CVF. Associations between metabolic risk factors and CVF quartiles were assessed by ANOVA, as were the associations between clustering of metabolic risk factors and CVF quartiles. Differences of metabolic risk factors among CVF quartiles were assessed by Tukey's test. There was not a significant interaction between pubertal development and CVF.

The CVF threshold to discriminate between either a low or high metabolic risk by ROC curve was calculated. ROC curve is a plot of all the sensitivity/ specificity pairs resulting from varying the decision threshold (22). Sensitivity (or true-high rate) is the proportion of the sample correctly identified as having a high metabolic risk. Specificity is the proportion of subjects correctly identified as having a low metabolic risk. On the $y$ axis, sensitivity is plotted, and, on the $x$ axis, is the 1 - specificity (false-high rate). False-high rate is the proportion of subjects having a low metabolic risk that have been incorrectly identified as having a high metabolic risk. The perfect test that correctly classifies all subjects has a true-high rate of 1 and false-high rate of 0 . Therefore, the optimal combination of true-high rate and false-high rate is the point closest to the perfect test (upper left corner of the graph). To identify the best threshold, the distance between the perfect test and each sensitivity and 1 - specificity pair was calculated, and, then, the pair closest to 1 was chosen. The AUC and 95\% confidence interval (CI) were calculated. The AUC represents the ability of the test to correctly classify children having a low/high metabolic risk. The values of AUC range between 1 (perfect test) to 0.5 (worthless test). Finally, binary logistic regression was used to study the relationship between metabolic risk and CVF. All analyses were performed using the Statistical Package for Social Sciences (SPSS, version 13.0 for Windows; SPSS Inc., Chicago, IL), and the level of significance was set at $\alpha=0.05$.

\section{RESULTS}

None of the analyzed variables showed a statistically significant difference between the included subjects and the subjects who did not provided a whole set of data. Valid CVF data were obtained in $85 \%$ of the studied subjects. Pubertal development status was obtained from $96 \%$ of the children; 97\% had blood pressure measurements and $98 \%$ had blood measurements. The descriptive characteristics of the study sample are shown in Table 1. One way ANOVA showed that, in girls, skinfold thickness, insulin, and triglycerides decreased across CVF quartiles, whereas, in boys, skinfold thickness and insulin decreased across CVF quartiles (Table 2). The clustering of metabolic risk factors also decreased across CVF quartiles in both girls and boys (Fig. 1). Tukey's test showed that, in girls, skinfold thickness was $22 \%, 27 \%$, and $36 \%$ higher in the first CVF quartile (i.e. lowest and/or worst CVF quartile) compared with the second, third, and fourth CVF quartiles (i.e. highest and/or best CVF quartiles), respectively. In boys, skinfold thickness was $26 \%, 31 \%$, and $40 \%$ higher in the first CVF quartile compared with the second, third, and fourth CVF quartiles, respectively. Insulin values were $1 \%, 15 \%$, and $21 \%$ higher in the first CVF quartile compared with the second, third, and fourth CVF quartiles in girls, respectively. In boys, insulin values were $23 \%, 13 \%$, and $20 \%$ higher in the first CVF quartile compared with the second, third, and fourth CVF quartiles, respectively. Triglyceride values were $13 \%$ higher in the first CVF quartile

Table 1. Baseline characteristics of 873 children (444 girls, 429 boys)

\begin{tabular}{lccr}
\hline & \multicolumn{1}{c}{ All } & Girls & \multicolumn{1}{c}{ Boys } \\
\hline Age (y) & $9.6(0.4)$ & $9.5(0.4)$ & $9.6(0.4)$ \\
Height $(\mathrm{m})$ & $1.38(0.6)$ & $1.38(0.7)$ & $1.38(0.6)$ \\
Weight $(\mathrm{kg})$ & $32.1(5.8)$ & $32.0(6.2)$ & $32.1(5.5)$ \\
BMI $\left(\mathrm{kg} / \mathrm{m}^{2}\right)$ & $16.7(2.1)$ & $16.7(2.3)$ & $16.8(2.0)$ \\
Tanner \% (1/2/3/4/5) & $69 / 23 / 8 / 0 / 0$ & $54 / 44 / 2 / 0 / 0$ & $99 / 1 / 0 / 0 / 0$ \\
Sum of five skinfolds (mm) & $40.2(16.9)$ & $44.7(18.2)^{*}$ & $35.7(14.2)$ \\
Insulin (pmol/L) & $41.4(23.5)$ & $44.7(24.6)^{*}$ & $38.0(21.9)$ \\
Glucose (mmol/L) & $5.0(0.4)$ & $4.9(0.4)^{*}$ & $5.1(0.3)$ \\
HDLC $(\mathrm{mmol} / \mathrm{L})$ & $1.5(0.3)$ & $1.4(0.3)^{*}$ & $1.5(0.3)$ \\
Triglycerides (mmol/L) & $0.7(0.3)$ & $0.8(0.3)^{*}$ & $0.7(0.3)$ \\
Systolic BP (mm Hg) & $102.5(9.0)$ & $101.9(8.8)$ & $103.1(9.2)$ \\
Diastolic BP (mm Hg) & $60.4(7.1)$ & $60.6(7.0)$ & $60.1(7.3)$ \\
Metabolic risk score & $0.0(0.5)$ & $0.03(0.5)^{*}$ & $-0.03(0.5)$ \\
CVF (mL/kg/min) & $40.1(6.3)$ & $37.1(5.0)^{*}$ & $43.0(6.0)$ \\
\hline
\end{tabular}

Data shown as mean (SD).

$* p<0.01$ for differences between sexes. 
Table 2. Associations between metabolic risk factors and CVF quartiles in girls and boys

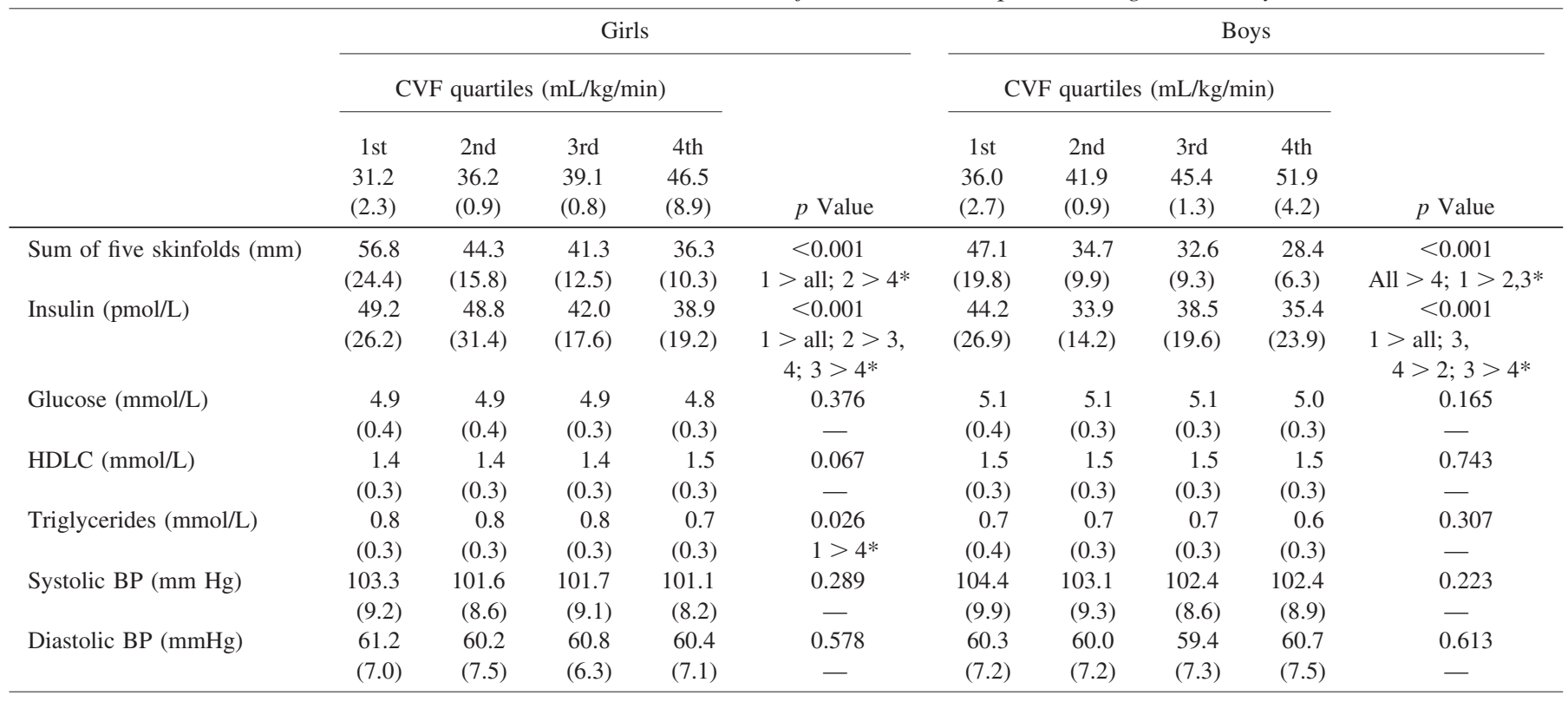

Data shown as mean (SD). $p$ Value determined by ANOVA. BP, blood pressure.

$* p<0.05$ from Tukey's test for differences among quartiles.

than in the fourth CVF quartile in girls (Table 2). The metabolic risk score was $12 \%, 23 \%$, and $29 \%$ higher in the first CVF quartile than in the second, third, and fourth CVF quartiles in girls, respectively, whereas, in boys, it was $23 \%$, $19 \%$, and $30 \%$ higher in the first CVF quartile than in the second, third, and fourth CVF quartiles, respectively (Fig. 1). The results did not change when skinfold thickness was adjusted for height.

ROC analysis showed a significant discriminating accuracy of CVF in identifying a low/high metabolic risk in girls (AUC $=0.68,95 \%$ CI: $0.62-0.73 ; p<0.001$ ), and in boys (AUC $=$ $0.67,95 \%$ CI: $0.61-0.73 ; p<0.001$ ) (Fig. 2). In girls, the optimal pair of true-high and false-high rates was 0.65 and

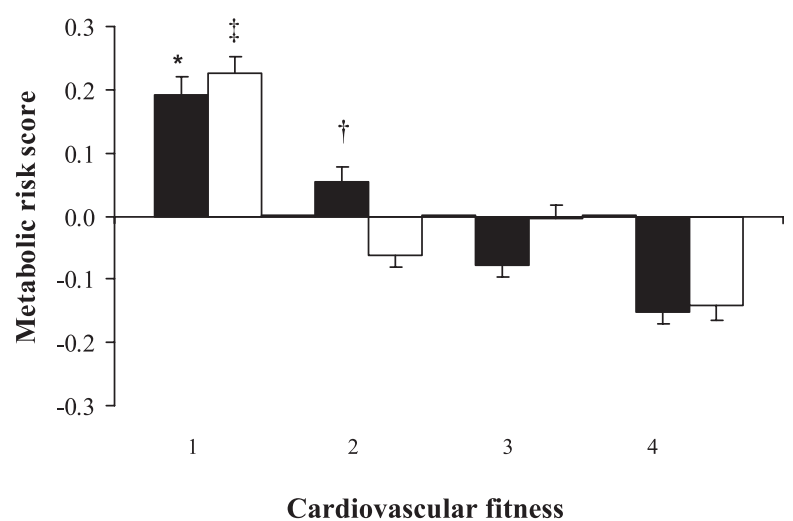

Figure 1. Associations of cardiovascular fitness (quartiles) with clustering of metabolic risk factors (metabolic risk score) in girls (black bars) and boys (white bars). Data shown as mean and SD. Girls in the first quartile $(*)$ had a higher metabolic risk score than in the second, third, and fourth quartiles ( $p=0.006, p=0.002, p<0.001$, respectively), and girls in the second quartile $(\dagger)$ had a higher metabolic risk score than in the fourth quartile $(p=$ 0.018 ). Boys in the first quartile $(\ddagger)$ had a higher metabolic risk score than in the second, third, and fourth quartiles $(p=0.007)$.
0.33 , respectively, and 0.65 and 0.39 in boys. The CVF values at these points were 37.0 and $42.1 \mathrm{~mL} / \mathrm{kg} / \mathrm{min}$ in girls and boys, respectively. Logistic regression analysis showed that girls with CVF levels above $37.0 \mathrm{~mL} / \mathrm{kg} / \mathrm{min}$ had an increased odds ratio of having a low metabolic risk when compared with those with CVF levels below this value (odds ratio, 3.09; 95\% CI: $1.98-4.82 ; p<0.001)$. Boys with CVF levels above 42.1 $\mathrm{mL} / \mathrm{kg} / \mathrm{min}$ had an increased odds ratio of having a low metabolic risk than those with CVF levels below this value (odds ratio, 2.42; 95\% CI: 1.56-3.76; $p<0.001$ ). The CVF levels and the odds ratios remained the same when the low metabolic risk was considered to be at $<1 \mathrm{SD}$ (data not shown). However, the AUC was slightly bigger than the AUC obtained when the cutoff was established at $<75$ th percentile for both genders (data not shown). Because no interaction was found by country, all the analyses were performed with Estonia and Sweden together to have a stronger statistical power. In addition, the results remained similar when the analyses were performed separately for countries.

\section{DISCUSSION}

The main findings of this study were that CVF is associated with clustering of metabolic risk factors in children. Moreover, the results suggest a hypothetical CVF level for having a low metabolic risk. Having health criterion values for CVF from an early age is of special interest because it can be used to quantify another risk factor for cardiovascular disease in primary prevention and health promotion policies. CVF values could be also adopted by the schools as a "fitness standard" to encourage children to engage in physical activity to achieve and go beyond the required CVF levels. Because the roots of cardiovascular diseases have been found in childhood (23), lifestyle modification during these years may be effective in lowering cardiovascular disease risk in later life. 

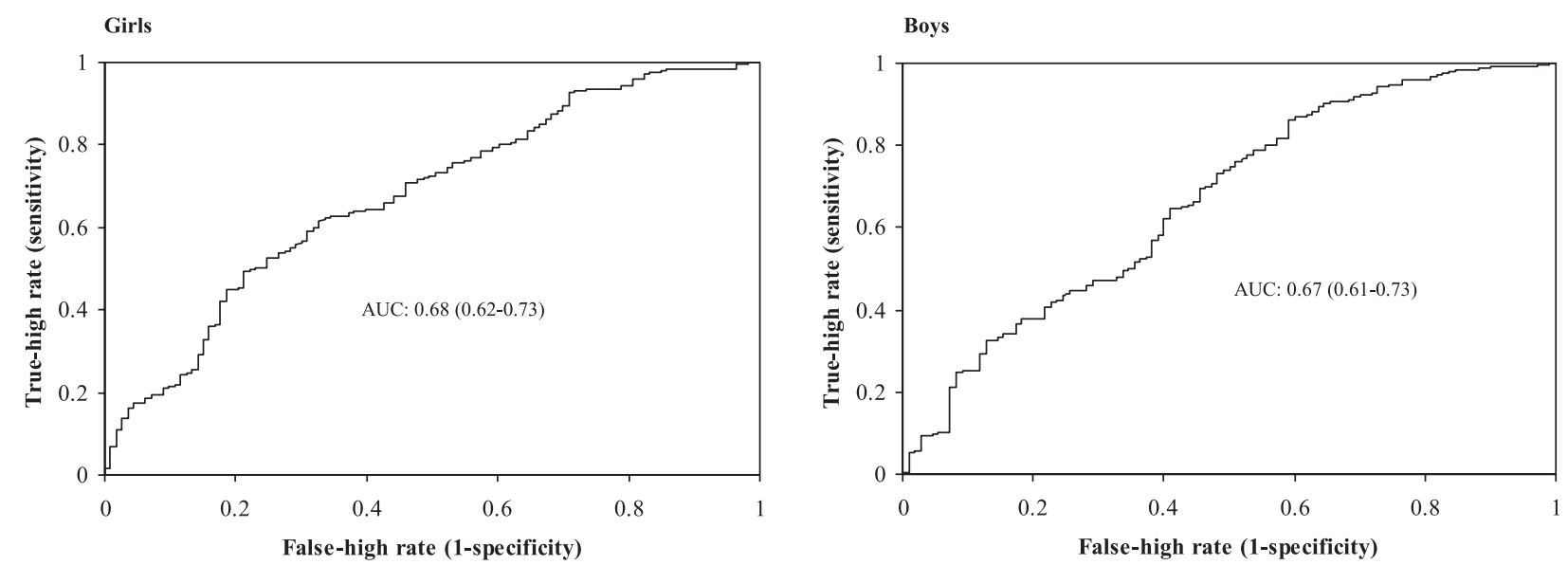

Figure 2. ROC curve summarizing the potential of CVF to identify low/high metabolic risk score in girls and boys. AUC indicates the area under the curve (95\% CI).

CVF has a large genetic component (up to 40\%) (24). However, it is mainly determined by a person's activity level (4,25-27). Recent findings have shown that variation in CVF was significantly explained by at least moderate to vigorous [3-6 metabolic equivalents (MET)] physical activity (4). Further analysis revealed that children who engaged in at least 26 $\mathrm{min} / \mathrm{d}$ of vigorous ( $>6 \mathrm{MET}$ ) physical activity had significantly higher CVF than those who accumulate $10-18 \mathrm{~min} / \mathrm{d}$ of vigorous physical activity. Taken together, these results suggest that those children with a CVF level below that required to have a low metabolic risk may be able to reach the desirable CVF level with adequate aerobic physical activity.

There is no standard pediatric definition of the metabolic syndrome. Several attempts have been made in adolescents aged 12-19 y by using criteria analogous to Adult Treatment Panel (ATP) III (28-30). Other approaches have been made elsewhere to compute a metabolic risk to signify a clustering of metabolic risk factors in healthy Danish children aged 9-10 y (2). The risk score computed here is similar to that which was reported previously (2) because of similarities in ages of the studied subjects and methodology, and because no one child involved in the present study had three or more abnormalities in any of the parameters included in the ATP III definition (data not shown). The risk score computed here was arbitrarily dichotomized defining children having values equal or above 75th percentile of the score as being at high risk. The same percentile has been used in different health-related variables (e.g. waist circumference, BMI, triglycerides, insulin levels, systolic blood pressure, total cholesterol to HDLC ratio, plasma leptin, etc.) in a number of population-based studies to define subjects at low $(<75$ th) or high $(\geq 75$ th) risk $(31,32)$. Even if none of the children had clinical disease, a high metabolic risk may not be a desirable condition.

The test used to measure CVF has been previously validated in children of the same age (20), and it was highly correlated with directly measured $\mathrm{VO}_{2 \max }(r=0.95$ and $r=$ 0.90 in girls and boys, respectively) (21). Maximum tests have been shown to be more accurate than submaximal tests to predict $\mathrm{VO}_{2 \max }$ (33). CVF was expressed as $\mathrm{VO}_{2 \max }$ per kilogram of body mass because of the homogeneity in age, pubertal status, height, weight, and obesity grade of the children, and for the purpose of comparing the results with previous publications.

Previous studies in children and adolescents have shown associations between CVF and cardiovascular risk factors (2-6), whereas others failed to find associations between CVF and features of metabolic syndrome in overweight Latino youths aged $8-14 \mathrm{y}$ with a positive family history of type 2 diabetes (30). Direct associations between increased CVF and clustering of metabolic risk factors in both girls and boys have been shown here, similar to another recent study in Danish children of the same age (2). Associations between increased $\mathrm{CVF}$ and a favorable lipid profile and fasting glycemia in both overweight and nonoverweight Spanish adolescents (the AVENA study) showed a similar situation, and the main outcome was that CVF was an indicator of a favorable plasma lipid profile in male adolescents (3).

In the AVENA study, ROC analysis showed a significant discriminatory accuracy of age- and sex-normalized CVF to identify either the presence or absence of a favorable plasma lipid profile in males but not in females (3). The similar ROC analysis performed in the present study showed a significant discriminatory accuracy of CVF to identify either a low or high metabolic risk in both girls and boys (Fig. 2). Girls with CVF levels above $37.0 \mathrm{~mL} / \mathrm{kg} / \mathrm{min}$ were 3.09 times more likely of having a low metabolic risk when compared with those with CVF levels below this value. Similarly, boys with CVF levels above $42.1 \mathrm{~mL} / \mathrm{kg} / \mathrm{min}$ were 2.42 times more likely to have a low metabolic risk when compared with those with CVF levels below this value. Taken together, these results suggest that high CVF is associated with low metabolic risk in children.

The mathematically calculated CVF levels in our study are similar to the health-related CVF threshold suggested by worldwide recognized organizations $(11,12)$. Based on expert judgment, the European Group of Pediatric Work Physiology considered a $\mathrm{VO}_{2 \max }$ of $\geq 35 \mathrm{~mL} / \mathrm{kg} / \mathrm{min}$ for girls and $\geq 40$ $\mathrm{mL} / \mathrm{kg} / \mathrm{min}$ for boys as a "Health Indicator" (11). The Cooper Institute for Aerobics Research suggested $\geq 38$ and $\geq 42 \mathrm{~mL} /$ $\mathrm{kg} / \mathrm{min}$ for girls and boys, respectively, as a criterion standard 
for the "Healthy Fitness Zone" (12). The cut-off points proposed by the Cooper Institute for adolescents were extrapolated from the thresholds established for adults. The approaches used to calculate the CVF thresholds were different in the previous studies and in our study, as well as the measured outcomes, age, and cultural and social factors of the study subjects. However, the similarities among the results support the existence of a hypothetical health criterion value for CVF in children.

The percentage of the population failing to reach the required level of CVF is of concern and suggests the need to interpret with prudence the meaning of these values. Among girls, $44 \%$ did not reach the CVF level, and neither did $40 \%$ of the boys. Longitudinal studies are needed to show whether those children having a CVF above the suggested values have a lower incidence of cardiovascular diseases later in life than those having a CVF below the suggested value.

The observations of the present study are limited by the cross-sectional design nature, i.e. direction of causality cannot be determined. The CVF fitness test requires relatively minor equipment (i.e. cycle-ergometer and a heart rate monitor) and can be easily performed in a clinical setting. However, a maximal test requires a maximal effort be made, which may not be adequate for a population with clinical pathology. The low AUC observed in this study together with the modest odds ratio for having a low metabolic risk in subjects with low/high CVF levels may indicate a low discriminatory ability for identifying children likely to have a high metabolic risk. However, it must be kept in mind that the children involved in this study were apparently healthy children with no previously diagnosed cardiovascular pathologies. We also do not know whether an extrapolation of the association may be made for children with subclinical manifestations of cardiovascular pathology. Nevertheless, with regular reports of increasing childhood metabolic-related diseases prevalence worldwide, the results of this study are noteworthy. The inclusion of a large number of subjects of the same age and the objective measurement of CVF are notable strengths of this study.

In conclusion, the present study shows that CVF is associated with clustering of metabolic risk factors in children. Moreover, the results suggest a hypothetical CVF level for having a low metabolic risk. The CVF levels shown here are similar to the health-related threshold values of CVF suggested by the European Group of Pediatric Work Physiology (11), and by the Cooper Institute for Aerobics Research (12). From a clinical point of view, these results add supporting evidence to the body of knowledge indicating the importance of having a high CVF from an early age. Longitudinal and/or intervention studies are needed to examine the impact of having low CVF in childhood on the likelihood of having cardiovascular diseases later in life.

Acknowledgments. This work is dedicated to the late Maarike Harro, University of Tartu and the National Institutes of Health Development, Tallinn, Estonia. The authors thank Olle Carlsson for statistical assistance and Pekka Oja for highly valuable comments, both guest scientists at our unit.

\section{REFERENCES}

1. Taylor HL, Buskirk E, Henschel A 1955 Maximal oxygen uptake as an objective measure of cardiorespiratory performance. J Appl Physiol 8:73-80

2. Brage S, Wedderkopp N, Ekelund U, Franks PW, Wareham NJ, Andersen LB, Froberg K; European Youth Heart Study (EYHS) 2004 Features of the metabolic syndrome are associated with objectively measured physical activity and fitness in Danish children: the European Youth Heart Study (EYHS). Diabetes Care 27:21412148.

3. Mesa JL, Ruiz JR, Ortega FB, Warnberg J, González-Lamuño D, Moreno LA, Gutiérrez A, Castillo MJ 2006 Aerobic physical fitness in relation to blood lipids and fasting glycaemia in adolescents. Influence of weight status. Nutr Metab Cardiovasc Dis 16:285-293

4. Ruiz JR, Rizzo NS, Hurtig-Wennlöf A, Ortega FB, Warnberg J, Sjöström M 2006 Relations of total physical activity and intensity to fitness and fatness in children; The European Youth Heart Study. Am J Clin Nutr 84:299-303

5. Reed KE, Warburton DE, Lewanczuk RZ, Haykowsky MJ, Scott JM, Whitney CL, McGavock JM, McKay HA 2005 Arterial compliance in young children: the role of aerobic fitness. Eur J Cardiovasc Prev Rehabil 12:492-497

6. Twisk JW, Kemper HC, van Mechelen W 2002 The relationship between physical fitness and physical activity during adolescence and cardiovascular disease risk factors at adult age. The Amsterdam Growth and Health Longitudinal Study. Int J Sports Med 23:S8-S14

7. Andersen LB, Harro M, Sardinha LB, Froberg K, Ekelund U, Brage S, Anderssen SA 2006 Physical activity and clustered cardiovascular risk in children: a crosssectional study (The European Youth Heart Study). Lancet 368:299-304

8. Carnethon MR, Gidding SS, Nehgme R, Sidney S, Jacobs DR, Liu K 2003 Cardiorespiratory fitness in young adulthood and the development of cardiovascular disease risk factors. JAMA 290:3092-3100

9. LaMonte MJ, Barlow CE, Jurca R, Kampert JB, Church TS, Blair SN 2005 Cardiorespiratory fitness is inversely associated with the incidence of metabolic syndrome: a prospective study of men and women. Circulation 112:505-512

10. Katzmarzyk PT, Church TS, Blair SN 2004 Cardiorespiratory fitness attenuates the effects of the metabolic syndrome on all cause and cardiovascular disease mortality in men. Arch Intern Med 164:1092-1097

11. Bell RD, Macek M, Rutenfranz J, Saris WH 1986 Health indicators and risk factors of cardiovascular diseases during childhood and adolescence. In: Rutenfranz J, Mocelin R, Klimt F (eds) Children and Exercise XII. Human Kinetics, Champaign, IL, pp 19-27

12. The Cooper Institute for Aerobics Research 1999 FITNESSGRAM Test Administration Manual. Human Kinetics, Champaign, IL, pp 38-39

13. Riddoch C, Edwards D, Page A, Froberg K, Anderssen SA, Wedderkopp N, Brage S Cooper AR Sardinha LB, Harro M, Klasson-Heggebø L, van Mechelen W, Boreham C, Ekelund U, Bo Andersen L, and the European Youth Heart Study Team 2005 Cardiovascular disease risk factors in children: rationale, aims, study, design, and validation of methods. J Phys Activ Health 2:115-129.

14. Wennlöf AH, Yngve A, Sjöström M 2003 Sampling procedure, participation rates and representativeness in the Swedish part of the European Youth Heart Study (EYHS). Public Health Nutr 6:291-299

15. Ekelund U, Sardinha LB, Anderssen SA, Harro M, Franks PW, Brage S, Cooper AR, Andersen LB, Riddoch C, Froberg K 2004 Associations between objectively assessed physical activity and indicators of body fatness in 9- to 10-y-old European children: a population-based study from 4 distinct regions in Europe (the European Youth Heart Study). Am J Clin Nutr 80:584-590

16. Allison DB, Zhu SK, Plankey M, Faith MS, Heo M 2002 Differential associations of body mass index and adiposity with all-cause mortality among men in the first and second National Health and Nutrition Examination Surveys (NHANES I and NHANES II) follow-up studies. Int J Obes Relat Metab Disord 26:410-416

17. Gutin B, Litaker M, Islam S, Manos T, Smith C, Treiber F 1996 Body-composition measurement in 9-11-y-old children by dual-energy X-ray absorptiometry, skinfold thickness measurements, and bioimpedance analysis. Am J Clin Nutr 63:287-292

18. Tanner J 1962 Growth at Adolescence. Blackwell, Oxford, UK

19. Park MK, Menard SM 1987 Accuracy of blood pressure measurement by the Dinamap monitor in infants and children. Pediatrics 79:907-914

20. Wennlöf AH, Yngve A, Nilsson TK, Sjöström M 2005 Serum lipids, glucose and insulin levels in healthy schoolchildren aged 9 and 15 years from Central Sweden: reference values in relation to biological, social and lifestyle factors. Scand J Clin Lab Invest 65:65-76

21. Hansen HS, Froberg K, Nielsen JR, Hyldebrandt N 1989 A new approach to assessing maximal aerobic power in children: the Odense School Child Study. Eur J Appl Physiol Occup Physiol 58:618-624

22. Zweig MH, Campbell G 1993 Receiver-operating characteristic (ROC) plots: a fundamental evaluation tool in clinical medicine. Clin Chem 39:561-577

23. Berenson GS, Srinivasan SR, Bao W, Newman WP, Tracy RE, Wattigney WA 1998 Association between multiple cardiovascular risk factors and atherosclerosis in children and young adults: the Bogalusa Heart Study. N Engl J Med 338:1650 1656

24. Wolfarth B, Bray MS, Hagberg JM, Perusse L, Rauramaa R, Rivera MA, Roth SM, Rankinen T, Bouchard C 2005 The human gene map for performance and healthrelated fitness phenotypes: the 2004 update. Med Sci Sports Exerc 37:881-903

25. Mahon AD, Vaccaro P 1994 Cardiovascular adaptations in 8- to 12-year-old boys following a 14-week running program. Can J Appl Physiol 19:139-150

26. Ignico AA, Mahon AD 1995 The effects of a physical fitness program on low-fit children. Res Q Exerc Sport 66:85-90 
27. Gutin B, Yin Z, Humphries MC, Barbeau P 2005 Relations of moderate and vigorous physical activity to fitness and fatness in adolescents. Am J Clin Nutr 81:746-750

28. Cook S, Weitzman M, Auinger P, Nguyen M, Dietz WH 2003 Prevalence of a metabolic syndrome phenotype in adolescents: findings from the third National Health and Nutrition Examination Survey, 1988-1994. Arch Pediatr Adolesc Med 157:821-827

29. de Ferranti SD, Gauvreau K, Ludwig DS, Neufeld EJ, Newburger JW, Rifai N 2004 Prevalence of the metabolic syndrome in American adolescents: findings from the Third National Health and Nutrition Examination Survey. Circulation 110:24942497

30. Shaibi GQ, Cruz ML, Ball GD, Weigensberg MJ, Kobaissi HA, Salem GJ, Goran MI 2005 Cardiovascular fitness and the metabolic syndrome in overweight Latino youths. Med Sci Sports Exerc 37:922-928
31. Chu NF, Wang DJ, Shieh SM, Rimm EB 2000 Plasma leptin concentrations and obesity in relation to insulin resistance syndrome components among school children in Taiwan-The Taipei Children Heart Study. Int J Obes Relat Metab Disord 24:1265-1271

32. Wyszynski DF, Waterworth DM, Barter PJ, Cohen J, Kesaniemi YA, Mahley RW, McPherson R, Waeber G, Bersot TP, Sharma SS, Nolan V, Middleton LT, Sundseth SS, Farrer LA, Mooser V, Grundy SM 2005 Relation between atherogenic dyslipidemia and the Adult Treatment Program-III definition of metabolic syndrome (Genetic Epidemiology of Metabolic Syndrome Project). Am J Cardiol 95:194198

33. McArdle WD, Katch FI, Kattch VL 2006 Exercise Physiology: Energy, Nutrition and Human Performance, 6th Ed. Lippincott Williams \& Wilkins, Philadelphia, pp $240-246$ 